\title{
PROCESSOS DE TERRITORIALIZAÇÃO EMPRESARIAL NA AMAZÔNIA: SIGNIFICADOS E DECORRÊNCIAS
}

\author{
Business territorialization processes in the Amazon region: meanings and consequences
}

\author{
Luis Fernando Novoa Garzon \\ Doutor em Planejamento Urbano e Regional. \\ Universidade Federal de Rondônia, Porto Velho, Brasil \\ I.novoa@unir.br \\ (1) http://orcid.org/0000-0003-2280-7959 \\ Daniele Severo da Silva \\ Especialista em Sociologia e Ensino de Sociologia. \\ Universidade Federal de Rondônia, Porto Velho, Brasil \\ danielessevero@gmail.com \\ Maíra Silva Ribeiro \\ Graduada em Ciências Biológicas \\ Universidade Federal de Rondônia, Porto Velho, Brasil \\ silvaribeiro.maira@gmail.com
}

A lista completa com informações dos autores está no final do artigo

\section{RESUMO}

Esse artigo pretende elencar pistas acerca dos dispositivos práticos e simbólicos (medidas funcionalizadoras do espaço promovidas em nome do "progresso") adotados no processo de implementação de grandes hidrelétricas na região amazônica, que vem contribuindo para o rebaixamento dos padrões de proteção ambiental e de direitos sociais e territoriais vigentes no país. Os agentes estruturadores dos "territórios empresariais" resultantes desses empreendimentos procuram produzir espaços funcionais, precedidos de limpezas sociais profundas que expressam a natureza privatista e autoritária inerente a esses processos de incorporação espacial de larga escala. Tais processos, contudo, não se dão sem contendas e antagonismos, seja entre os segmentos condutores da reestruturação espacial-social, seja entre estes e a população deslocada compulsoriamente que insiste em resgatar margens de autonomia do viver coletivo, a partir de repertórios culturais que não se encerram e de novas sociabilidades que se abrem. Nesses termos, o conflito territorial é posto e reposto, não como "obstáculo" ou "entrave", mas como interrogante acerca das próprias metas e resultados dos projetos de "modernização" e "desenvolvimento". Nossa proposição é fornecer elementos analíticos e espaços de reconhecimento para o (re)mapeamento de tradições e resistências nas novas condições colocadas pelo contínuo reescalonamento do espaço produzido por grandes projetos já implementados e em implementação na Amazônia.

PALAVRAS-CHAVE: Conflitos territoriais. Grandes projetos hidrelétricos. Riscos ambientais. Paradigmas de estudos ambientais. Comunidades ribeirinhas amazônicas.

\begin{abstract}
We propose to investigate the practical and symbolic apparatuses, adopted in the process of implementation of large hydroelectric dams in the Amazon region, which has contributed to the lowering of environmental protection standards and social and territorial rights in force in the country. The structuring agents of the "business territories" resulting from these endeavors seek to produce functional spaces, preceded by deep social cleansing, which express the privatizing and authoritarian nature inherent in these processes of large-scale spatial incorporation. However, these processes do not come about without disputes and antagonism. Theses tensions exist between the segments that lead the spatial-social restructuring or between them and the compulsorily displaced population, which insists on rescuing margins of autonomy from collective living, from cultural repertoires that are not closed and new sociabilities that open up. In these terms, territorial conflict is postulated and re-postulated, not as an "obstacle" but as a question about the very goals and results of the "modernization" and "development" projects. We propose to provide analytical elements and recognition of spaces for the (re)mapping of traditions and resistance in the new conditions posed by the continuous rescheduling of the space produced by large-scale projects already implemented and under implementation in the Amazon region.

KEYWORDS: Territorial conflicts. Large hydropower projects. Environmental risks. Paradigms of environmental studies. Amazon riverside communities.
\end{abstract}




\section{INTRODUÇÃO}

A região amazônica tem cumprido um rebaixado papel de suporte e aprofundamento de um determinado regime de acumulação (BOYER, 1990) fundado no uso intensivo de recursos naturais, na flexibilização de direitos territoriais e de normativas ambientais e na precarização e desvalorização da força de trabalho. O lugar dos capitais na fila das incorporações territoriais é sempre negociável: a abertura de fronteiras para novos e mais profundos negócios com bens/direitos sociais e ambientais depende do grau de interpenetração entre capitais e Estado e do alcance das bonificações mútuas.

Ao longo dos últimos 50 anos, a região amazônica foi sendo acossada por dinâmicas de incorporação compulsória, seja de caráter governamental-geopolítico, seja de caráter governamental-empresarial, seja de caráter não-governamental, intergovernamental e/ou multilateral, como se pode verificar no Quadro 1 a seguir.

Quadro 1 - Programas viabilizadores e normalizadores de processos de incorporação econômico-territorial da Amazônia

\begin{tabular}{|l|l|l|}
\hline $\begin{array}{l}\text { Intervenções de caráter } \\
\text { governamental-geopolítico }\end{array}$ & $\begin{array}{l}\text { Intervenções de caráter } \\
\text { governamental-empresarial }\end{array}$ & $\begin{array}{l}\text { Intervenções de caráter não- } \\
\text { governamental e/ou } \\
\text { multilateral }\end{array}$ \\
\hline $\begin{array}{l}\text { Projeto de Integração Nacional } \\
\text { (PIN) - 1970 }\end{array}$ & $\begin{array}{l}\text { Eixos Nacionais de Integração e } \\
\text { Desenvolvimento (ENIDs) -1996 }\end{array}$ & $\begin{array}{l}\text { Programa Piloto para Proteção } \\
\text { das Florestas Tropicais (PPG7) - } \\
1990\end{array}$ \\
\hline $\begin{array}{l}\text { Programa de Pólos } \\
\text { Agropecuários e Agrominerais } \\
\text { da Amazônia (POLAMAZÔNIA) }\end{array}$ & $\begin{array}{l}\text { Implementação de corredores } \\
\text { de exportação contidos no } \\
\text { Programa de Aceleração do } \\
\text { Crescimento (PAC) - 2006 }\end{array}$ & $\begin{array}{l}\text { Iniciativa para Conservação da } \\
\text { Bacia Amazônica (ABCI) - 2005 }\end{array}$ \\
\hline $\begin{array}{l}\text { Projeto Calha Norte (PCN) - } \\
1985\end{array}$ & $\begin{array}{l}\text { Programa de Investimentos em } \\
\text { Logística (PIL) - 2012 }\end{array}$ & $\begin{array}{l}\text { Governança e Infraestrutura na } \\
\text { Amazônia (GIA) - 2018 }\end{array}$ \\
\hline $\begin{array}{l}\text { Sistema de Vigilância da } \\
\text { Amazônia (SIVAM) - 2002 }\end{array}$ & $\begin{array}{l}\text { Programa de Parceria de } \\
\text { Investimentos (PPI) - 2016 }\end{array}$ & \\
\hline
\end{tabular}

Fonte: Elaborado pelo autor.

As dinâmicas sócio-territoriais deflagradas por estes Programas - ressalvando-se espaços intersticiais no âmbito de programas multilaterais - invariavelmente desprezaram encadeamentos econômicos intrarregionais duradouros, pouco se comprometeram com a singularidade cultural e com o bem-estar da população amazônica e vetaram qualquer protagonismo das comunidades tradicionais no planejamento e condução desses processos.

A Amazônia foi assim reconcebida discursivamente e desenhada espacialmente por meio desses programas-dispositivos. O conceito de dispositivo (FOUCAULT, 1997) como um aparato de vigilância integral (material-simbólica) propicia uma visualização minuciosa 
da genealogia da homogeneização do bloco no poder em função dos interesses vinculados à exportação de recursos naturais. A produção normativa das bancadas setoriais (do agronegócio, da mineração, das construtoras) nas últimas legislaturas, as (re)regulamentações implementadas pelos ministérios (Ministérios de Minas e Energia, Agricultura e Transportes) e agências reguladoras capturadas, e, por fim, a jurisprudência formada na segunda e terceira instância do sistema judicial. Normatizações ou vedações todas elas enunciadas e legitimadas em nome do progresso e do desenvolvimento da própria Amazônia e da nação.

Foi desse modo que a Amazônia converteu-se em um cardápio de enclaves instalados e por instalar. Grandes empresas localizadas na região ascendem como fornecedoras mundiais de larga escala (global supplier) de matérias-primas e para isso contam com a maleabilidade crescente dos marcos regulatórios dos setores de energia, mineração e de infraestrutura, além da celeridade dos processos de apropriação e internacionalização de terras (land grabbing) (FLEXOR \& LEITE, 2017)

A capacidade diferencial dos setores que representam os interesses dos setores de commodities contrasta com a capacidade das populações locais de incidir na pretensão mínima de fazer cumprir marcos protetivos elementares. Trata-se de modus operandi político-econômico que se vale ora do assistencialismo e de políticas semipúblicas (responsabilidade social-empresarial) ora da repressão e vigilância de organizações populares.

Ainda que seja por agregação conceitual, cabe provisoriamente descrever o modelo econômico hegemônico no Brasil como "rentista-neoextrativista" (CARVALHO et al., 2018), ao qual o país foi entregue nas últimas décadas; modelo este que combina reiteradas expropriações primárias ao longo da fronteira econômica com formas espoliativas de última geração. A discricionaridade que foi franqueada às empresas nas últimas concessões minerárias, energéticas e dos setores de infraestrutura - especialmente a partir de 2016 seguramente não se justifica por algum tipo de amadurecimento social e institucional das concessionárias privadas.

Não são apenas os capitais estritamente referidos que almejam vantagens locacionais, mas os próprios locais (e regiões/países) é que oferecem vantagens através da flexibilização da legislação e das políticas sociais e ambientais. Políticas macroeconômicas e de atração de investimento são sustentadas por meio de ações micropolíticas de consentimento, ou seja, o controle corporativo se enraíza na subjetividade e no cotidiano das pessoas e dos grupos sociais. Benson \& Kirsch (2010) designam como 
"política de resignação" a construção, por agentes empresariais e governamentais, de cenários de inevitabilidade dos processos de expansão das relações mercantis e das espoliações subsequentes que alimentam na população uma percepção de impotência e incredulidade quanto a qualquer outra postura que não seja a de adequação e de adesão pragmática às dinâmicas monopolistas vigentes.

Expressam-se na região amazônica, por isso, diagramas cambiantes de forças sociais e gestos de demonstração de superação de barreiras - físicas e simbólicas: o lastro que se quer oferecer para fidelizar investimentos e grupos de investidores. Novas parcerias entre capitais e reconfigurações passam a ser fundadas na garantia de dinamismos adicionais e extraordinários para a realização de valor. Se a meta que reveste a dinâmica de aumento da taxa de exploração é a "redução do custo-país", o que pode significar a redução do "custo Amazônia" senão a oferta de subsídios regulatórios e territoriais para atrair investimentos incondicionados?

\section{TERRITÓRIOS EMPRESARIAIS, DESASTRES E HOMOGENEIZAÇÃO ESPACIAL}

Detendo-se sobre os grandes projetos minerais na Amazônia, Filho Sevá (2010) designa os receptáculos espaciais dos polos minero-metalúrgicos como "territórios empresariais de dimensões regionais". O retrospecto de desterritorialização das "Amazônias minerais", já por muitos mapeado e detalhado, não seria diferente das "Amazônias hidrelétricas", especialmente porque se retroalimentam, em ordem direta e reversa.

O território empresarial instaura seus próprios espaços de jurisdição que depois o Estado vai legitimando - seja pelos vazios do licenciamento e do planejamento público, seja pela avalização de acordos pontuais na forma de Termos de Ajustamento de Conduta. O caminho fica livre assim para a desfiguração de multivariadas territorialidades, fazendo com que medidas de indenizações, mitigações dos impactos e outras medidas compensatórias sejam percebidas como dádivas. A territorialidade a que nos referimos é aquela que se enuncia a partir da memória resultante de interações sucessivas entre uma dada coletividade e seu meio ambiente imediato. Com todas as prerrogativas garantidas de antemão, os grupos empresariais iniciam sua territorialização de mão única como "a territorialização do monopólio e a monopolização do território" (OLIVEIRA, 2004, p. 43). 
Exemplar nesse sentido foi o esgarçamento da legislação ambiental para que se aprovasse tanto o licenciamento das hidrelétricas no rio Madeira (UHEs Santo Antônio e Jirau) como no rio Xingu (UHE Belo Monte). Processo considerado prototípico "de uma tendência no Brasil para a flexibilização das exigências ambientais e abreviação do processo de licenciamento" (FEARNSIDE, 2014, p. 1); nos marcos de uma "trajetória de autolicenciamento dos empreendimentos privados com diligente chancela 'pública' que os imuniza contra eventuais contestações jurídicas" (NOVOA GARZON, 2008, p. 45).

Em um contexto tão propício à "irresponsabilidade organizada" ${ }^{\text {, fenômenos }}$ extremos que atingem o rio e sua bacia somente podem provir da "natureza" desse mesmo processo. Os desastres decorrentes e seus efeitos socialmente diferenciados proporcionam novas apropriações "regulares", seja para cumprir funções logísticas para grandes empresas, seja para servir a áreas de lazer e/ou ao paisagismo gentrificador. Nessa modalidade de ajuste espacial, as comunidades camponesas e ribeirinhas e bairros "beiradeiros" têm sido os destinatários preferenciais dos danos socioambientais, tidos como danos colaterais de um padrão de acumulação focado em commodities e em plantas industriais eletrointensivas.

\section{UHES JIRAU E SANTO ANTÔNIO COMO TERRITÓRIOS DE EXCEÇÃO: APONTAMENTOS TEÓRICO-METODOLÓGICOS}

O caso das usinas no rio Madeira demonstra que o setor elétrico foi encaixado ferreamente nos marcos dos investimentos privados. Inventários e estudos de encomenda, licenças licenciosas, operação antecipada, incluindo um limite mínimo/máximo de direitos e compensações nos entornos das UHEs.

A dam industry (SEVÁ, 2012; BERMANN; HERNANDES, 2010) é reconhecidamente perita em transformar bens de uso potencialmente comum em direitos monopolistas de apropriação territorial. Conta para isso com uma institucionalidade elástica o suficiente para que possa vigorar, em qualquer tempo, a "democracia direta do capital" (VAINER, 2013), em especial por ocasião de megaprojetos. São suspensões do tempo e do espaço, ou

\footnotetext{
${ }^{1}$ A irresponsabilidade organizada consubstancia-se quando se opta deliberadamente por dissimular as ameaças e os riscos socioambientais, permitindo que se normalizem sem alarde, contando que tais práticas limítrofes não serão reveladas ou invalidadas (BECK, 1995).
} 
ajustes espaço-temporais que permitem uma intensificação do ritmo da acumulação, com base na queima e na criação de novos campos de valorização e mercadorização.

Territórios de exceção, tal como na "cidade de exceção" categorizada por Carlos Vainer (VAINER, 2011), implicam em um regime de renúncia ou de rearranjo permanente à última linha de força estabelecida pelos seus controladores privados majoritários. A política de exceção permanente tornou-se cotidiana e os acordos sobre o que deve ser o rio Madeira e sua bacia, a cidade de Porto Velho e seus distritos e nucleamentos ribeirinhos são feitos por cima, em posição política considerada suficientemente concentrada para expressar o perfil atualizado dos processos de concentração econômica.

Os grandes projetos esgarçam as já corroídas regulações públicas, como as normativas da política ambiental ou previstas no Estatuto das Cidades. O ambiental e o urbano enquanto porção dos "territórios empresariais" simplesmente cedem o território como plataforma física para grandes negócios no presente e no futuro.

Esta pesquisa se propõe a demonstrar, com maior concretude e detalhamento, os caminhos institucionais e discursivos específicos em que vai se forjando uma temerária prática jurisprudencial, que precifica e nivela por baixo os padrões de proteção ambiental e de direitos sociais e culturais vigentes no país.

Do ponto de vista metodológico, o artigo é uma pesquisa qualitativa de nível exploratório, com vistas a tornar o objeto de estudo mais explícito. Quanto aos procedimentos, trata-se de uma pesquisa documental, além de uma pesquisa de campo. Para a coleta de dados foram utilizadas as técnicas da pesquisa qualitativa, sendo a entrevista semiestruturada a principal delas, bem como observações diretas (CHAUVIN \& JOUNIN, 2015).

A identificação de práticas empresariais auto-legitimadas, de legislações específicas, ou de descumprimentos reiterados que indicam a existência de normas informais operando a territorialização privada foi feita com base em pesquisa documental disponibilizada pelo IBAMA e BNDES e também a partir de entrevistas com representantes do Movimento Atingidos por Barragens (MAB), lideranças de comunidades deslocadas ou em deslocamento e técnicos e dirigentes do IBAMA, no nível estadual e federal ${ }^{2}$.

Faz-se preciso situar os usos dominantes dos indicadores de "sustentabilidade" manejados pelos Consórcios Santo Antônio Energia e Energia Sustentável do Brasil. As

\footnotetext{
2 Tendo esta pesquisa caráter qualitativo e exploratório, foram aqui apresentados resultados parciais que compõem um programa de investigação mais amplo realizado no âmbito do Grupo de Pesquisa

Territorialidades e Imaginários na Amazônia.
} 
soluções a que chegaram não podem ser apresentadas simplesmente como um "avanço progressivo e previsível" da ciência e tecnologia. São soluções apenas no sentido de fórmulas retóricas que anunciam a internalização de ponderações ambientais para legitimar previamente processos de crescimento econômico. Conceitos antes desveladores são constantemente usurpados por aqueles que precisam densificar suas máscaras.

O processo de ambientalização ${ }^{3}$, ao expropriar o sentido das perdas, acelera as expropriações de territorialidades e modos de vida. Esse agendamento vertical de um meio ambiente com "efeitos comuns a todos" demonstra a conversão da questão ambiental em um campo de legitimação estratégico para reciclar o discurso dominante e ao mesmo tempo para desenraizar a crítica. É uma antecipação que procura mapear potenciais fatores de atravancamento na implementação dos grandes projetos e proporcionar os devidos canais para o "tratamento de conflitos".

Por isso, apesar dos avanços institucionais propagandeados, predomina uma agenda de cooptação de lideranças locais e silenciamento dos conflitos. A cooptação de grupos menos poderosos por grupos mais poderosos é recorrente quando a posição intermediadora é espetacularizada como espaço de participação nas decisões e de divisão do bolo dos benefícios sociais. É decorrência do maior consenso empresarialgovernamental em torno dos negócios baseados em recursos territorializados (água, energia, florestas, terra e subsolo) um maior nível de pressão para instrumentalizar órgãos públicos e para cooptar movimentos sociais e organismos sociais locais.

A forma de licenciamento e implementação das UHEs Santo Antônio e Jirau representa exemplarmente o que pode ser uma construção política de situações de mercado. Em outros termos, interessa entender suportes estatais específicos a processos de incorporação e acumulação capitalistas, na observação atenta dessa manutenção artificial da mercantilização, que Tapia e Araújo (2011) retraduziram como um processo de "reincorporação administrativa à forma-mercadoria".

Quando consórcios viabilizados pelo suporte de empresas públicas, de fundos de pensão e do BNDES se comportam da forma mais privatista concebível, fazendo mais do mesmo quando podiam fazer o contrário, estabelece-se a égide de um privatismo integral, ou de um "neoliberalismo enraizado". Para Cerny (2008), um neoliberalismo assim

\footnotetext{
${ }^{3}$ Leite Lopes (2006, p. 34) define a "ambientalização" como um processo de premeditada "interiorização pelas pessoas e pelos grupos sociais das diferentes facetas da questão pública do 'meio ambiente"', o que acarreta alteração na forma e na modulação dos conflitos, bem como sua "institucionalização parcial".

4 "Administrative recommodification", estratégia que no original estaria explicitada no DekommodifizierungsTheorem de Offe (BORCHERT; LESSENICH, 2004, p. 564).
} 
capilarizado estabelece condições mais restritivas de reversibilidade, por sua natureza poliforme e adaptável, reformulando o campo de forças e as regras em que se confrontam e se calculam as estratégias políticas e econômicas dos atores.

Compensações oficiais para os governos municipal e federal - até as indenizações - sofreram alterações no percurso. Desinformação estratégica, negociação individualizada, desincentivo de articulação da população, cooptação de líderes e criminalização do protesto foram algumas das situações apontadas por lideranças dos movimentos sociais, e que perduram até hoje. Um dirigente ${ }^{5}$ do Movimento dos Atingidos por Barragens, avalia que

O licenciamento foi tipo um ritual para garantir que a empresa se instalasse no território e viabilizasse a construção (...). Então, parece que o licenciamento não existe, ele é uma letra morta, ele serve em alguns momentos para a gente usar de apoio para fazer a luta e ser menos criminalizado, porque tem um amparo legal; fora isso, não serve para nada.

Para a blindagem judicial e política dos grandes projetos de infraestrutura no Brasil, não foi indiferente uma relativa expansão de programas sociais conexos geridos por movimentos sociais, dessa forma apassivados. Na "dialética da passivização"6, a ordem procura debilitar preventivamente a contra-ordem para melhor assimilá-la. As aparentes concessões econômico-corporativas traduziram-se na prática em margens mais estreitas para negociar revisões e reparações ao longo dos processos de implementação dos empreendimentos. O duro aprendizado que deriva dessa experiência é a percepção da impossibilidade de obtenção de patamares mínimos de justiça social e ambiental por meio de canais institucionais tão somente.

As tratativas com a população afetada diretamente pelas obras ou pelos lagos das UHEs ilustram esse quadro de cristalização político-administrativa dos desígnios empresariais. As medidas oferecidas foram: indenização, carta de crédito e reassentamento. Entretanto, os reassentamentos nem de longe recompuseram as condições de reprodução material e simbólica que as famílias tinham, e as medidas indenizatórias, do modo como foram conduzidas, se tornavam sem efeito. Houve, por parte dos Consórcios, deliberada cooptação e esfacelamento de organização social. As ações de indenização viraram um balcão de negócios comandado por intermediários jurídicos que recebiam bônus maiores dos consórcios a depender da extensão da adesão aos acordos lesivos oferecidos aos atingidos.

\footnotetext{
${ }^{5}$ Entrevista concedida por João Marcos Dutra (MAB-RO) em 07 de maio de 2018.

6 Nos termos de Braga (1996, p. 11), trata-se de uma dialética "que catalisa um reformismo 'pelo alto', conservador, mas ao mesmo tempo abrindo caminhos para recomposições e ajustes internos.
} 
Tal como apontado, quanto mais dependentes de investimentos estrangeiros e multinacionais forem os países, mais tolerarão ou coparticiparão de violações socioambientais geradas por essas corporações. A decorrência lógica é a flexibilização de leis e normas que alimenta a constituição de territórios empresariais que vão criando seus próprios espaços de jurisdição. À medida que as negociações avançam, as regras de proteção social e ambiental são secundarizadas diante das outorgas e concessões feitas às grandes empresas. Para Almeida (2010), as estratégias acionadas pelos interesses vinculados ao neoextrativismo têm por fim expandir seu domínio sobre amplas extensões de terra e território. Essas estratégias se refazem e se atualizam no âmbito dos distintos poderes (Legislativo, Judiciário e Executivo) nas três esferas (Federal, Estadual e Municipal) visando enfraquecer os dispositivos constitucionais que asseguram os direitos territoriais das comunidades camponesas e tradicionais.

\section{AÇÕES E ESTRATÉGIAS EMPRESARIAIS DE UMA GRANDE HIDRELÉTRICA: UM OLHAR A PARTIR DE UMA COMUNIDADE ATINGIDA}

Dentro da proposta estabelecida para este trabalho, a partir de elementos materiais e simbólicos, foram investigadas as práticas dos consórcios Santo Antônio Energia e Energia Sustentável do Brasil a partir de entrevistas com agentes públicos que mantiveram e mantêm relações com tais empresas e com a população por eles afetada. A política do referido Consórcio alterou profundamente o cotidiano de ribeirinhos localizados no Município de Porto Velho, para além do deslocamento produzido pelos lagos e pelas obras. O deslocamento de maior espectro produzido é aquele que afeta e inviabiliza os calendários socioculturais das comunidades tradicionais ribeirinhas, fortemente vinculados aos ciclos dos rios amazônicos sem barramentos.

De forma mais específica, apontaremos visões de pessoas pertencentes à comunidade Maravilha, localizada a jusante do Rio Madeira, que foi afetada por processos de desbarrancamento a partir de 2012 e depois foi praticamente arrasada pela cheia de 2014. Visualizados como moradores em "área de risco", muitos passaram a residir em outras localidades, como podemos perceber no exposto:

hoje em dia eu moro na cidade, na verdade, mas os meus pais estão lá e eu podia acompanhar todo esse processo que teve da cheia, né? (...) também 
lá, alagou tudo lá, teve casa que ficou soterrada, pessoas que inclusive foram morar lá em casa na época e muitos ficaram desabrigados, né? (MORADOR A $)^{7}$

A partir dos relatos de alguns ribeirinhos, foi possível constatar que diversos moradores deixaram seus sítios para morar no perímetro urbano de Porto Velho. Fatores vinculados à renda e emprego foram os que mais pesaram nessas decisões. À medida que tais deslocamentos foram se sucedendo, sem qualquer acompanhamento ou amparo de políticas públicas específicas, fizeram-se notar expressivas descontinuidades e rupturas sociais e culturais. O deslocamento compulsório sempre produzirá uma situação-limite ou trauma, a esticar o tecido do que foi vivido até o limite do irreconhecível, borrando as imagens e autoimagens nele tecidas.

Ficar lá, né? Não tem condições pra comprar uma outra casa na cidade num lugar mais (legal) e tamo vivendo lá, tamo nessa batalha todo ano lá, torcendo pra que o barranco não caia mais e vamo levando a vida lá do jeito que a gente pode. Não tá muito boa a nossa vida lá não, mas graças a Deus lá enquanto tiver um pedacinho de terra a gente tá lá porque abandonar mesmo não pretendo abandonar não, que eu já nasci e me criei lá, mas não pretendo sair (...) de lá não, porque eu já fui no tempo da enchente sai de lá e passei 2 anos fora e não foi bom a convivência fora, né? Não era muito longe da, de onde eu morava não, mas não é como a gente morava no sítio que a gente pode ter a liberdade da gente... a gente lá (...) a gente tá preso, não tem, não tem condições de sair e ir pra lá não; é só isso o que tenho pra falar mesmo. (MORADOR B)

As interações entre ribeirinhos e os Consórcios foram marcadas por conflitos não assumidos na sua amplitude, invariavelmente amortecidos por lideranças cooptadas e/ou por representantes do poder local. Os custos de "readequação" do modo de vida foram devidamente socializados, como (re)plantar suas roças em locais sem a mesma fertilidade das várzeas perdidas, (re)construir suas casas sem vegetação circundante e em uma disposição desagregada dos laços de vizinhança anteriores, entre outros elementos vinculados à integridade psicossocial dessas pessoas.

Ao ouvir representantes familiares (reputados dessa forma pelas famílias), notamos que há uma luta simbólica já conflagrada pelo direito de existir singularmente em cenário de negação das possibilidades de viver na barranca do Madeira, de plantar, cultivar em sua várzea rarefeita, de pescar o peixe para comer e o peixe para vender, de trafegar com sua canoa, de traçar e retraçar laços parentais e de afeto.

7 É necessário destacar que todas as referências, feitas doravante a nomes dos entrevistados, são substituídas por letras do alfabeto, escolhidas aleatoriamente. Tal procedimento foi utilizado com vistas a resguardar a identidade dos entrevistados frente ao furor higienista dos órgãos de defesa civil. 
Então por causa dessa enchente que aconteceu em 2014, perdeu tudo, não sobrou nada. A única coisa que eu consegui recuperar, recuperar não, tirar antes da enchente foi uma plaina que hoje em dia tá aqui na Arirambas [Associação cultural Arirambas], e o esmeril. Foi só, o resto do maquinário foi todo perdido, ficou todo enterrado debaixo da terra depois que desalagou. Então teve perda total na marcenaria, a única coisa que restou da Ariramba foi essa... aqui o que tá aqui desse lado, né? Porque aqui também impossível a água chegar aqui, né? Chegasse aqui acabava com a cidade inteira. Então a gente lá do outro lado da Arirambas não tem mais nada; onde tem alguma coisa de projeto que tem da Arirambas tem que ser feito agora desse lado, né? Porque o que tinha lá acabou, não tem mais nada. Então se tem que seguir os projetos da Arirambas tem que ser agora desse lado aqui. (MORADOR $\mathrm{C}$ )

Os moradores da comunidade Maravilha ${ }^{8}$ majoritariamente se posicionaram de forma contrária à construção das UHEs no rio Madeira, uma vez que não foram devidamente consultados, muito menos considerados no processo de licenciamento das obras. No período dos estudos referentes aos impactos causados aos ribeirinhos residentes à jusante do rio Madeira, mencionava-se que seriam afetados pela mudança do regime de vazão das águas. Depois da cheia, em quadro de um território arrasado, ficaram ainda mais patentes as percepções de impotência e de derrota por ser quem se é.

Com o decorrer das entrevistas realizadas com os moradores de Maravilha, foi possível observar a magnitude da necessidade de manter canais de diálogo abertos. Aqueles que persistem, lutam para a manutenção de sua subsistência, mantendo suas práticas, suas produções, mesmo com muitas dificuldades, não se desenraizam da comunidade ainda que esfacelada e agarram-se em suas memórias.

Uma das coisas que estive vendo através que veio nas enchentes e que também veio nas usinas, foi a perda da identidade cultural aqui do lugar porque... e aquele (...) que sabe (fazer) garrafa? Que sabe fazer na (empalhadeira). A pessoa não acha mais não; não acha mais não. Então assim, eu vejo é que isso... o, o principal problema aqui que sofre a comunidade, tanto aqui o Maravilha, Niterói, Belmont, e (...) cidade. Essa ponte, essa ponte aí ficou completamente desatada aí, antigamente era uma trilha. Então eu acho que a principal que está sendo sofrida nesse lugar; a perda da identidade cultural e que se depois disso saio alguma coisa. Não tem porque a gente faz várias reuniões, mas espero que saia alguma coisa. (MORADOR Y)

8 Os moradores da comunidade Maravilha expressam uma identificação forte com seu território e não consideram deixar suas moradias e suas cosmologias. Na prática percebe-se que está em curso um processo de (re) construção da etnicidade em meio aos efeitos ocasionados pelos empreendimentos hidrelétricos. Desta forma, as definições e autodefinições dos membros da comunidade estão sendo recolocadas e reinventadas. 
Estes elementos dissipadores se deram em função de empreendimentos que divulgavam em seu processo inicial que gerariam energia para o país. O paradoxo é que, ao passo que as empresas avançavam em suas rotinas de convencimento, associaram sua existência à instauração de uma necessária e grandiosa fase de desenvolvimento na Amazônia, mas que benefícios pode trazer um desenvolvimento intransitivo, avesso a qualquer protagonismo local e regional? Os remanescentes pós-hidrelétricas atestam sua condição de estrangeiros em seu próprio país, párias sociais, sem lugar na pretensa "cadeia evolutiva" do progresso.

\section{CONSIDERAÇÕES FINAIS}

$\mathrm{Na}$ última década, os grandes projetos agropecuários, minerais e hidrelétricos de energia elétrica foram o esteio para mais um ciclo de apropriação econômica e de expropriação social na região Amazônica, particularmente nas bacias dos rios Xingu e Madeira. Procuramos destacar aqui aspectos da territorialização empresarial promovida particularmente nesta última bacia.

Procuramos destacar as visões e universos cognitivos que sustentaram esses processos expropriatórios bem como aspectos da territorialização empresarial promovida na bacia do rio Madeira a partir da construção das hidrelétricas de Santo Antônio e Jirau. A partir dos discursos e representações sociais analisadas, nota-se que há uma disputa de significados acerca do que seria desenvolvimento ou espoliação da Amazônia, o que implica em distintas capacidades de percepção e de inteligibilidade do território recriado.

\section{REFERÊNCIAS}

ALMEIDA, Alfredo Wagner. Agroestratégias e desterritorialização: direitos territoriais e étnicos na mira dos estrategistas dos agronegócios. In: ALMEIDA, A. W. et al. (orgs.). Capitalismo globalizado e recursos territoriais: fronteiras da acumulação no Brasil contemporâneo. Rio de Janeiro: Lamparina, 2010.

BECK. U. Ecological politics in an age of risk. Cambridge, Polity Press, 1995.

BENSON, Peter; KIRSCH, Stuart. Capitalism and the Politics of Resignation. Current Anthropology, Volume 51, Number 4, August 2010.

BERMANN, C.; HERNANDES, F. A usina de Belo Monte: energia e democracia em questão. Revista Política Democrática, n. 27, 2010, p. 43 - 57. 
BOYER, R. A Teoria da Regulação. São Paulo: Nobel, 1990.

BORCHERT, J.; LESSENICH, S. Spätkapitalismus revisited: Claus Offes Theorie und die adaptive Selbsttransformation der Wohlfahrtsstaatsanalyse. Zeitschrift für Sozialreform/Journal of Social Policy Research, 50(6), 563-583.

BRAGA, Ruy. Risorgimento, Fascismo e americanismo: a dialética da passivização. In: FERNANDES, E. et al. (orgs.). O Outro Gramsci. São Paulo: Xamâ, 1996. p. 167-182.

CARVALHO, Alba Maria Pinho; MILANEZ, Bruno; GUERRA, Eliana. Rentismoneoextrativismo: a inserção dependente do Brasil nos percursos do capitalismo mundializado (1990-2017). In: RIGOTTO, R. M. et al. (orgs.) Tramas para a justiça ambiental: diálogo de saberes e práxis emancipatórias. Fortaleza: Edições UFC, 2018. p. 19-58.

CHAUVIN, Sébastien; JOUNIN; Nicolas. A observação direta. In: PAUGAM, S. (coord.). A pesquisa sociológica. Tradução de Francisco Morás. Petrópolis, RJ: Vozes, 2015. p. 124140.

CERNY, Philip G. Embedding neoliberalism: the evolution of a hegemonic paradigm. The Journal of International Trade and Diplomacy, v. 2, n.1, 2008, p. 1-46.

FEARNSIDE, P. Barragens do rio Madeira - Sedimentos 2: O primeiro cenário oficial. Amazônia Real, 05 de maio de 2014. Disponível em: http://amazoniareal.com.br/barragensdo-rio-madeira-sedimentos-2-o-primeiro-cenario-oficial/. Acesso em: 28 jul. 2014.

FLEXOR, Georges; LEITE, Sérgio. Mercado de terra, commodities boom e land grabbing no Brasil. In: MALUF, Renato S.; FLEXOR, Georges Flexor (orgs.). Questões agrárias, agrícolas e rurais: conjunturas e políticas públicas. Rio de Janeiro: E-Papers, 2017. p. $20-39$.

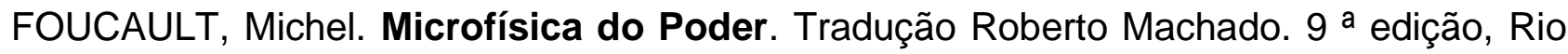
de Janeiro: Ed. Graal, 1997.

LEITE LOPES, José Sérgio. Sobre processos de "ambientalização" dos conflitos e sobre dilemas da participação. Horizontes Antropológicos, n. 25, 2006. p. 31-64.

NOVOA GARZON, Luiz Fernando. O licenciamento automático dos grandes projetos de infra-estrutura no Brasil: o caso das Usinas no rio Madeira. Universidade e Sociedade, ano XVIII, № 42, DF, 2008.

NOVOA GARZON, Luiz Fernando. Usinas hidrelétricas aceleram 'territorialização corporativa' da Amazônia. Correio Cidadania, 2010. Disponível em: http://www.correiocidadania.com.br/economia/5310-17-12-2010-usinas-hidreletricasaceleram-territorializacao-corporativa-da-amazonia. Acesso em: 20 ago. 2019.

OLIVEIRA, Ariovaldo Umbelino. O Campo no Século XXI. São Paulo: Editora Casa Amarela, São Paulo, 2004 
OSÓRIO, Jaime. Padrão de reprodução do capital: uma proposta teórica. In: FERREIRA, C.; OSORIO, J.; LUCE, M. (orgs.) Padrão de reprodução do capital. São Paulo: Boitempo, 2012, 37-86.

FILHO SEVÁ, Arsenio Oswaldo. Problemas intrínsecos e graves da expansão mineral, metalúrgica, petrolífera, e hidrelétrica nas Amazônias. In: ZHOURI, A.; LASCHEFSKI, K. (orgs.). Desenvolvimento e conflitos ambientais. Belo Horizonte: Editora UFMG, 2010.

FILHO SEVÁ, Arsenio Oswaldo. Capitalismo hidrelétrico em Minas Gerais: o Rio Grande e seus afluentes silenciados. In: NOGUEIRA et al. Universidade Tecnologia e Sociedade. Viçosa: UFVJM, 2012, p. 1-39.

TAPIA, Jorge. R. B.; ARAÚJO, A. M. B. Estado, classes e estratégia: notas sobre um debate. Crítica e Sociedade. V.1, n.1, Uberlândia, jan-jun, 2011. p. 9-54.

VAINER, C. B. Cidade de exceção: reflexões a partir do Rio de Janeiro. Apresentação Mesa Redonda "Política Urbana/Planejamento territorial". Anais XIV Encontro Nacional da ANPUR - Rio de Janeiro, maio de 2011.

VAINER, C. B. Quando a cidade vai às ruas. In: MARICATO, Ermínia et. al. Cidades Rebeldes: Passe Livre e as manifestações que tomaram as ruas do Brasil. São Paulo: Boitempo, 2013. p. 35-40.

\section{NOTAS}

\section{Luis Fernando Novoa Garzon}

Doutor em Planejamento Urbano e Regional

Universidade Federal de Rondônia, Grupo de Pesquisa Territorialidades e Imaginários na Amazônia, Porto Velho, Brasil

I.novoa@unir.br

(1) http://orcid.org/0000-0003-2280-7959

\section{Daniele Severo da Silva}

Especialista em Sociologia e Ensino de Sociologia

Universidade Federal de Rondônia, Porto Velho, Brasil

danielessevero@gmail.com

\section{Maíra Silva Ribeiro}

Graduada em Ciências Biológicas

Universidade Federal de Rondônia, Porto Velho, Brasil

silvaribeiro.maira@gmail.com

Endereço de correspondência do principal autor

Avenida Farquar, 3328, 76.801-466, Porto Velho- RO, Brasil.

\section{CONTRIBUIÇÃO DE AUTORIA}

Concepção e elaboração do manuscrito: L. F. N. Garzon, D. S. Silva, M. S Ribeiro

Coleta de dados: D. S. Silva, M. S Ribeiro

Análise de dados: L. F. N. Garzon, D. S. Silva, M. S Ribeiro

Discussão dos resultados: L. F. N. Garzon, D. S. Silva, M. S Ribeiro

Revisão e aprovação: L. F. N. Garzon

\section{CONJUNTO DE DADOS DE PESQUISA}

O conjunto de dados que dá suporte aos resultados deste estudo não está disponível publicamente.

\section{FINANCIAMENTO}

Não se aplica. 
CONSENTIMENTO DE USO DE IMAGEM

Não se aplica.

\section{APROVAÇÃO DE COMITÊ DE ÉTICA EM PESQUISA}

Não se aplica.

\section{CONFLITO DE INTERESSES}

Não se aplica.

LICENÇA DE USO - uso exclusivo da revista

Os autores cedem à Revista Internacional Interdisciplinar INTERthesis os direitos exclusivos de primeira publicação, com o trabalho simultaneamente licenciado sob a Licença Creative Commons Attribution (CC BY) 4.0 International. Estra licença permite que terceiros remixem, adaptem e criem a partir do trabalho publicado, atribuindo o devido crédito de autoria e publicação inicial neste periódico. Os autores têm autorização para assumir contratos adicionais separadamente, para distribuição não exclusiva da versão do trabalho publicada neste periódico (ex.: publicar em repositório institucional, em site pessoal, publicar uma tradução, ou como capítulo de livro), com reconhecimento de autoria e publicação inicial neste periódico.

PUBLISHER - uso exclusivo da revista

Universidade Federal de Santa Catarina. Programa de Pós-graduação Interdisciplinar em Ciências Humanas. Publicação no Portal de Periódicos UFSC. As ideias expressadas neste artigo são de responsabilidade de seus autores, não representando, necessariamente, a opinião dos editores ou da universidade.

EDITORES - uso exclusivo da revista

Javier Ignacio Vernal, Silmara Cimbalista e Selvino José Assmann (In Memoriam).

EDITOR ASSISTENTE - Eixo temático: "Amazônia: povos, conflitos e preservação"

Luiz Barp

HISTÓRICO - uso exclusivo da revista

Recebido em: 21-11-2019 - Aprovado em: 31-03-2020 - Publicado em: 13-04-2020 